\title{
Pessoas com deficiência: concursos públicos e cotas
}

\begin{abstract}
ADRIANA PAGAIME*
\section{RESUMO}

Com o objetivo de investigar a transição escola/mercado de trabalho das pessoas com deficiência - seja física, auditiva, visual, mental ou mista -, este estudo, norteado pela lei de cotas (reserva de vagas para pessoas com deficiência) analisa os resultados de três concursos públicos, realizados em 2005, 2006 e 2007, para verificar se as pessoas com deficiência dependem exclusivamente de cotas e permanecem concorrendo entre si. Os resultados indicaram que o número de pessoas com deficiência que buscaram inserçáo no mercado de trabalho, no serviço público, aumentou, porém ainda não atingiu $1 \%$ do total de inscritos. A análise, comparando os resultados obtidos nas provas, sugere que os candidatos que se declaram com deficiência teriam chances remotas de ingresso na carreira pública, se não amparados legalmente pelas cotas.
\end{abstract}

Palavras-chave: Deficientes, Sistema de cotas, Concurso, Mercado de trabalho.

\section{RESUMEN}

Con el objetivo de investigar la transición escuela/mercado de trabajo de las personas con deficiencia - sea física, auditiva, visual, mental o mixta -, este estudio, orientado por la ley de cuotas (reserva de vacantes para personas con deficiencia) analiza los resultados de tres concursos públicos, realizados en 2005, 2006 y 2007, para verificar si las personas con deficiencia dependen exclusivamente de las cuotas y si compiten entre sí. Los resultados indicaron que el número de personas con deficiencia que buscaron una inserción en el mercado de trabajo, en el servicio público, aumentó. Sin embargo, todavía no ha llegado al $1 \%$ del total de inscriptos.

* Departamento de Execução de Projetos da Fundaçáo Carlos Chagas (apagaime@uol.com.br). 
El análisis, comparando los resultados obtenidos en las pruebas, sugiere que los candidatos que se declaran con deficiencia tendrían chances remotas de ingresar a la carrera pública, si no estuvieran amparados legalmente por el sistema de cuotas.

Palabras clave: Deficientes, Sistema de cuotas, Concurso, Mercado de trabajo.

\section{ABSTRACT}

In order to investigate the transition of people with disabilities - whether physical, hearing, visual, mental or mixed - from school to the job market, this study, driven by Brazilian Federal law of quotas (a reservation of openings for people with disabilities), analyzes the results of three open public service recruitment exams, held in 2005, 2006 and 2007, in order to check if people with disabilities rely exclusively on quotas and keep competing with each other. The results indicated that the number of people with disabilities who seek integration into the job market, in the public service, has increased, but has not yet reached $1 \%$ of total applicants. The analysis, comparing the results of the exams, suggests that candidates who declare themselves disabled have remote chances of entering a public service career if not legally supported by quotas.

Keywords: Persons with disabilities, Quota system, Open public service recruitment, Job market.

128 • Est. Aval. Educ., São Paulo, v. 21, n. 45, p. 127-144, jan./abr. 2010 


\section{INTRODUÇÃO}

Este artigo tem como tema as relaçóes entre a educação e o mercado de trabalho, em especial da educação de pessoas com deficiência (seja física, auditiva, visual, mental ou mista). Trata-se de um estudo comparativo do desempenho obtido nos concursos públicos, entre as pessoas com e sem deficiência.

Ao agregar educação/educação inclusiva e mercado de trabalho, há breve relato apontando as Políticas Públicas Educacionais no amparo aos Direitos das Pessoas com Deficiência. Neste momento se dá o recorte da investigação: pessoas com deficiência e o direito ao trabalho (no serviço público), tendo como base o Decreto Federal no 3.298/99, que determina as cotas a serem cumpridas nos setores público e privado.

A definição pelos concursos públicos deu-se principalmente pelo fato da isonomia e impessoalidade da seleção pública. De acordo com a lei de cotas, deve haver reserva de vagas em todos os cargos. Já no setor privado, cada empresa pode eleger sua forma de contratação e, cumprindo sua cota, estipular quais cargos/funçóes serão ocupados por pessoas com deficiência.

Esta pesquisa justifica-se pela importância em se discutir o que podemos observar, passados 14 anos dos anseios de uma "Educação para Todos".

À luz da Declaração de Salamanca (1994) e do Decreto Federal no 3.298 de 1999 (lei de cotas), tínhamos como hipótese inicial que a demanda de pessoas com deficiência em busca do mercado de trabalho, no caso, em concursos públicos, havia aumentado consideravelmente, produto da lei e dos esforços investidos na área da educação.

A relação escola/trabalho e os motivos já expostos levaram ao problema da pesquisa: "o ingresso das pessoas com deficiência no mercado de trabalho, em especial no serviço público, depende exclusivamente de cotas?"

Para este estudo tivemos como base o banco de dados de uma instituição responsável pela realizaçáo das provas de concursos públicos em todo território nacional, e a partir dos dados coletados iniciamos as análises, para tentar responder à problematização exposta.

\section{TRABALHO E EDUCAÇÃO: RELAÇÕES E SIGNIFICADOS DE QUALIFICAÇÃO PROFISSIONAL}

Segundo Ferretti (2004), a educação escolar apresenta-se sob dois aspectos, um preocupado com a formação plena do indivíduo, o que inclui a formação profissio- 
nal indiretamente, e outro com a educação voltada para a formação profissional, sendo que ambas perspectivas valem-se da noção de qualificaçáo.

Acrescenta, ainda, que o estudo das relaçóes entre educação e trabalho (tendo com referência a forma fordista de produção capitalista), historicamente, se aproxima de discussóes sobre trabalho em duas matrizes que se complementam e se antagonizam. A primeira voltada para o campo técnico, com uma proposta de formação profissional, influenciada pelo progresso técnico, respondendo à produçáo capitalista, e a outra enraizada na filosofia e na economia política de origem marxista, problematizando questóes de natureza econômica, filosófica, social ético-política, relacionadas não apenas à formação profissional, mas à formação humana, da qual a primeira também faz parte. Esta matriz levou estudiosos da sociologia e filosofia a proporem a educação, considerando não apenas a segmentação do trabalho e a alienação do trabalhador, mas seu pleno desenvolvimento como sujeito social.

As discussões em torno da qualificação, formação geral, formação profissional, em razão das mudanças ocorridas no campo do trabalho, refletiram, nos anos 1990, não só entre educadores que defendiam a formação plena, mas no mercado de trabalho que já esperava operários bem preparados tecnicamente e mais educados, no sentido amplo do termo (Ferretti, 2004).

A valorização do saber, das experiências individuais e coletivas, da força para resolução de problemas diários e a capacidade de mobilização dos conceitos para enfrentar problemas da própria produçáo foram incorporadas à produçáo, o que obrigou a repensar a qualificação, denominada "modelo de competências", que sugere além do conhecimento técnico (saber-fazer) a mobilização dos conhecimentos citados (saber-ser) (Ferretti, 2004). Para o autor, conferir maior importância à qualificação como relação social pode representar uma dificuldade para os educadores, e também um desafio.

Atualmente, o conceito de qualificaçáo está ligado à produtividade e à competitividade, além da consolidação da cidadania, o que implica concebê-la como formação humana mais abrangente (Tartuce, 2007).

Entendemos, então, que a educação escolar está diretamente relacionada à necessidade do mercado, ou seja, à economia do momento histórico vigente. Se num primeiro momento a ênfase era dada aos postos de trabalhos decorrentes do modelo fordista de produção, em tempos atuais, o posto de trabalho é substituído pela tecnologia, requerendo, assim, profissionais "competentes".

Azevedo (2004) faz uma crítica ao "educar para o trabalho", pois, segundo ele, uma educação de qualidade e igualitária teria como resultado menor evasão escolar 
e melhor qualificação para o ingresso no mercado de trabalho. Salienta, ainda, que sua proposta náo é converter problemas sociais em educacionais, mas evidencia que proporcionar a todos os cidadãos educação escolar com proposta inclusiva ${ }^{1}$ acarretaria melhora na transição para o mercado de trabalho.

Desse modo, podemos aproximar as consideraçóes sobre mercado de trabalho, pois mesmo que tenham perspectivas diferentes em suas abordagens não refutam a responsabilidade da escola, e cada vez mais relacionam a educação com a formação plena do indivíduo, como o caminho que realmente prepara para o exercício da cidadania.

Ao discutirmos educação inclusiva, o preparo para o exercício da cidadania remete à escola maior responsabilidade. Tendo em vista uma sociedade capitalista que atrela valores humanos à capacidade de produção, é necessário, na "inclusão escolar", educar para que, no momento da transição escola/mercado, de trabalho a pessoa com deficiência esteja inserida na sociedade, no mais amplo sentido da palavra.

\section{MERCADO DE TRABALHO: AS CONQUISTAS LEGAIS PARA A INCLUSÃO DAS PESSOAS COM DEFICIÊNCIA}

Diversos documentos internacionais foram assinados no sentido de proteger os direitos das pessoas com deficiência. Faremos breve relato do caminho que o Brasil tem percorrido para garantir tais direitos, em especial daqueles que privilegiam educação e trabalho.

É sabido que, historicamente, as pessoas com deficiência estiveram à margem da sociedade, lançadas a toda sorte de preconceitos. A luta pela garantia dos direitos básicos de cidadania tem aumentado gradativamente, e os termos utilizados, como inválido, defeituoso, desvalido, incapaz, que já denotavam preconceito, como se fossem pessoas dispensáveis ao cotidiano social produtivo ou pessoas sem valor, foram alterados (continuam sendo) em razão de pressóes dos movimentos sociais (Gugel, 2006).

Ressalte-se que os direitos das pessoas com deficiência são garantidos, como a qualquer cidadão brasileiro, pela Constituição Federal de 1988 que, por sua vez, em seu artigo 208, determina, como dever do Estado, garantir "atendimento educacional especializado aos portadores de deficiência”.

${ }^{1} \mathrm{O}$ autor, em seu artigo, refere-se à proposta inclusiva, considerando os marginalizados economicamente, ou seja, os alunos pobres. 
Tratando-se da inclusão no mercado de trabalho, o Decreto Federal no 914, de 6 de setembro de 1993, no Capítulo III, artigo 5ª aponta as Diretrizes da Política Nacional para a Integração da Pessoa Portadora de Deficiência (Brasil, 1993).

Na Conferência Mundial de Educação Especial, realizada em Salamanca, Espanha, representantes de 88 governos e 25 organizaçóes internacionais já discutiam sobre a educação inclusiva, reafirmando o compromisso da "Educação para Todos”. Esse documento, denominado Declaraçáo de Salamanca (1994), reconhece a necessidade e urgência de providências em relaçáo ao sistema regular de ensino e recomenda a preservaçáo do direito fundamental da educaçáo a todos, resguardadas as características de cada indivíduo.

No Brasil, dois anos depois, foi instituída a Década da Educação, com a promulgaçáo da LDB - Lei de Diretrizes e Bases no 9.394, de 1996, determinando metas que deveriam ser cumpridas no prazo de dez anos, a partir de um ano da publicação da referida lei. $\mathrm{O}$ artigo $3^{\circ}$ apresenta os princípios sob os quais o ensino deve ser ministrado e, em seu inciso XI, expóe vínculo entre a educação escolar, o trabalho e as práticas sociais. Destarte, a LDB vincula a educação especial a educandos com necessidades especiais, que inclui, mas não se refere exclusivamente às pessoas com deficiência, pois o aluno pode ter necessidade educativa especial e náo ser portador de deficiência, dada a amplitude do conceito de necessidades educacionais especiais, que abrange diversos segmentos da populaçáo, sendo o aluno com deficiência um desses segmentos.

Com relação à Política Nacional para Integração das Pessoas Portadoras de Deficiência, o já citado Decreto Federal no 3.298, de 20 de dezembro de 1999, que regulamenta a Lei $n^{\circ} 7.853 / 89$, estabelece normas que objetivam assegurar o pleno exercício dos direitos individuais e sociais das pessoas portadoras de deficiência. Esse Decreto traz a definição de deficiência (artigo $3^{\circ}$ e $4^{\circ}$ ), as competências do Conselho Nacional dos Direitos da Pessoa Portadora de Deficiência (Conade) e da Coordenadoria para Integração da Pessoa Portadora de Deficiência (Corde). É este decreto, também, que trata pormenorizadamente da atuaçáo de empresas em relação à contratação, ou seja, estabelece cotas a serem cumpridas, para definitivamente garantir o direito - dentre outros - ao trabalho (Brasil, 1999).

A retomada dos fatos que apresentam a influência do mercado de trabalho na educação, bem como o desenvolvimento de políticas públicas, fez-se necessária para que, no decorrer desta pesquisa, possamos traçar o perfil das pessoas com deficiência que têm concorrido a cargos públicos e analisar, de forma crítica, como a escola 
está "entregando" os alunos vindos do processo de inclusão para a sociedade e, em especial, para o competitivo mercado de trabalho.

\section{OS EDITAIS DE CONCURSOS}

Para melhor evidenciar as normas sobre as quais devem dispor os editais de concursos, ressaltamos que a reserva de vagas em concursos públicos é regida pelo Decreto Federal no 3.298/99 que determina as condiçóes específicas das cotas: assegurar à pessoa portadora de deficiência o direito de se inscrever em concurso público, em igualdade de condiçóes com os demais candidatos, para provimento de cargo cujas atribuições sejam compatíveis com a deficiência de que é portador.

Logo, o candidato, ao inscrever-se, declara ser ou não portador de deficiência. Entretanto, para concorrer às vagas reservadas, deverá encaminhar laudo médico comprobatório, bem como indicar adaptaçóes de local e de prova, se necessárias, conforme normas constantes do Edital do concurso.

Em relação à divulgação dos resultados, também há norma específica (artigo 42). Os editais de concursos devem prever a divulgação dos resultados em duas listas: a primeira contendo a classificação geral de todos os candidatos inscritos/habilitados, inclusive os portadores de deficiência (lista geral), e a segunda apenas os candidatos classificados, inscritos como portadores de deficiência (lista especial).

O referido decreto determina que haja reserva mínima de 5\% das vagas às pessoas portadoras de deficiência, arredondando-se para cima sempre que esse cálculo não for número inteiro.

Em concursos cujas vagas não são divulgadas e/ou são realizados para formação de "Cadastro Reserva", o edital deverá prever, no caso das vagas que surgirem, qual vaga será destinada ao primeiro candidato portador de deficiência habilitado. Por exemplo, a primeira vaga é destinada ao primeiro colocado no concurso (lista geral), a segunda vaga aberta ao primeiro classificado na lista especial, e as próximas nomeaçóes da lista especial dar-se-ão a cada intervalo de 20 vagas providas da lista geral.

Expressas todas as normas editalícias, em conformidade com o decreto citado, os candidatos deverão acompanhar as nomeaçóes, baseando-se nas duas listas de resultados do respectivo concurso, verificando a ordem classificatória e o cumprimento da cota de reserva de vagas. 


\section{INCLUSÃO COMO AÇÃO AFIRMATIVA NO BRASIL}

Este trabalho não abordará a inclusão no sentido de discutir como a escola tem atuado em relação a "receber o aluno na escola" e não discutirá também as questóes em torno do ambiente escolar (sala regular ou classe especial, por exemplo), ou mesmo as questóes que tangem à formação de professores, temas que merecem discussóes e pesquisas aprofundadas. Todavia, nesta pesquisa, teremos como norte o conceito e o sentido da inclusão escolar como integrantes do processo de preparação básica do aluno para o mercado de trabalho.

Tendo em vista que, entre todas as atividades, o trabalho é que está diretamente ligado à dignidade humana, por propiciar recursos necessários à subsistência, à realização pessoal e até a aceitação no meio social, abordaremos a inclusão como uma das formas de aproximar a relação escola/educação na perspectiva de que a escola deve assumir sua responsabilidade ao receber o aluno e prepará-lo para a vida em sociedade.

De acordo com Bueno (2008), dentre as políticas educacionais no mundo, a inclusáo pode ser considerada o tema mais candente; basta acompanhar as políticas internacionais, os discursos políticos, as açóes do governo e de muitas escolas. Enfim, segundo o autor, a inclusão escolar, que deve conduzir à inclusão no trabalho e na sociedade, está "na ordem do dia" e surge como a "nova missão da escola".

Nessa mesma perspectiva, Patto (2008) chama a atenção para o uso epidêmico da palavra "inclusão", principalmente em um momento em que o capitalismo "exclui um enorme contingente da população economicamente ativa e produz excedente de mão de obra, avançando em estereótipos e preconceitos", quais sejam: cor da pele, nível de escolaridade ou pessoa com deficiência.

Num momento de dispensa em massa do trabalho, fala-se o tempo todo em incluir. Resta saber em que termo. Este é o cerne da questão. Para respondê-la é preciso entender o processo de exclusáo sob o modo capitalista de produção ontem e hoje. (Patto, 2008, p.26)

No VII Seminário de Cegos, Batista (2007), em sua explanação sobre os direitos universais de igualdade e análise sobre educação e trabalho, definiu que o trabalho para o capital se resume em "transformar um ato criativo em potencialidades", e que o ensino "adestra" para dar conta da tecnicidade do trabalho. Daí a diferença entre a divisão técnica e a divisão social do trabalho. Afirmou, ainda, que, para o capital, a pessoa com deficiência é significada como "força não produtiva", ou "produtiva em menor escala”, que não interessa ao capital. Logo, sua inserção no mercado de

134 - Est. Aval. Educ., São Paulo, v. 21, n. 45, p. 127-144, jan./abr. 2010 
trabalho é dificultada, tendo ressaltado a responsabilidade da escola em incluir o aluno e prepará-lo para esta sociedade.

No que tange às perspectivas políticas da inclusão escolar, Bueno contesta o otimismo que apresenta a educação inclusiva como meta para a construção de uma sociedade inclusiva. Para o autor, uma educação verdadeiramente inclusiva não será alcançada numa sociedade excludente. Nessa ordem, está implícito que a sociedade jamais incorporará a todos, e terá, assim, que ser permanentemente inclusiva, o que vai de encontro à construção de uma sociedade democrática, que gradativamente incorporasse a "massa de deserdados produzidos por políticas injustas e de privilegiamento das elites sociais" (Bueno, 2008 p.57).

Se a inclusão não é, de fato, responsabilidade exclusiva da escola, e as perspectivas para o futuro apontam para uma sociedade excludente, sempre haverá a quem incluir na escola, e, do mesmo modo, na sociedade, pois a inclusão social se dá por meio do trabalho, e este também não será para todos (Bueno, 2008). De acordo com o autor, suas críticas não são no sentido de apontar as impossibilidades de se construir ou se investir em políticas de inclusão, mas de contribuir para que a história possa tomar um rumo diferente, para que o futuro seja no mínimo melhor que o presente.

À luz de tais consideraçóes e para responder as inquietaçóes que originaram esta pesquisa, faremos as análises, possíveis, dos resultados obtidos pelos candidatos inscritos e amparados pela lei de reserva de vagas às pessoas com deficiência.

\section{PROCEDIMENTOS DE PESQUISA}

Este trabalho teve como fonte de coleta de dados uma instituição responsável pela organização e aplicação de concursos públicos, configurada como privilegiada pela experiência em aplicação de provas em todo território nacional. Após autorização da superintendência da instituição para utilização dos dados estatísticos dos concursos por ela realizados, iniciou-se o processo de coleta de material. Definimos analisar os dados referentes a 2005, 2006 e 2007, coletados junto ao setor de documentação da instituição, observadas as publicações na Imprensa Oficial dos Editais de Divulgação dos Resultados (Diário Oficial do Município, Estado ou da União), bem como a lista dos aprovados no referido acervo.

Procedeu-se o levantamento do número total de inscritos em todos os concursos de 2005, 2006 e 2007, cujos editais previam a reserva de vagas para pessoas com deficiência. Caracterizamos a demanda de inscriçôes (com e sem deficiência) por gênero e por faixa etária. Foram analisados comparativamente os desempe- 
nhos (classificação) dos candidatos aprovados, com e sem deficiência, por meio das listas de resultados.

\section{CARACTERÍSTICAS DOS CANDIDATOS}

Levantamos 73 concursos nos anos de 2005, 2006 e 2007, totalizando 3.046 .162 candidatos e, dentre esses, 14.595 (0,47\%) se declararam portadores de deficiência. Do total de inscritos, $44,60 \%$ são do sexo masculino, ou seja, a maioria dos inscritos é de mulheres 55,40\%. Entre os inscritos como portadores de deficiência ocorre o inverso: $37,75 \%$ corresponde às mulheres, e o percentual de homens chega aos $62,25 \%$. Tem-se aqui um fato que merece análise mais aprofundada, ou seja, investigar porque as mulheres com deficiência buscam menos o mercado de trabalho por meio de concursos públicos.

A tabela 1 caracteriza os inscritos por faixa etária e mostra que até os 25 anos o percentual de candidatos equivale a $16,49 \%$ do total de inscritos como portadores de deficiência. Em relação ao total de inscritos o percentual atinge $31,10 \%$. Na faixa etária que corresponde à fase adulta, qual seja, dos 26 aos 40 anos, encontramos os maiores percentuais nos dois grupos estudados: $53,30 \%$ para o total de inscritos e $60 \%$ para os portadores de deficiência. Considerando o intervalo de 41 a 50 anos, enquanto o percentual do total de inscritos nessa faixa etária é de $12,73 \%$, no grupo dos inscritos como portadores de deficiência essa marca alcança os 19,26\%. Entre os candidatos com idade acima dos 51 anos, o percentual corresponde a 2,86\% para o total de inscritos e $4,34 \%$ para os portadores de deficiência.

Tabela 1 - Caracterização da demanda de candidatos inscritos durante os três anos estudados, por faixa etária

\begin{tabular}{l|c|c|c|c}
\hline \multicolumn{1}{c|}{ Faixa etária } & Total de Inscritos* & $\begin{array}{c}\text { \% } \\
\text { Total de inscritos* }\end{array}$ & $\begin{array}{c}\text { Inscritos } \\
\text { P. D.** }\end{array}$ & $\begin{array}{c}\text { \% } \\
\text { Inscritos P. D.** }\end{array}$ \\
\hline Até 25 anos & 947.563 & 31,10 & 2.406 & 16,49 \\
\hline De 26 a 40 anos & 1.623 .474 & 53,30 & 8.744 & 59,91 \\
\hline De 41 a 50 anos & 387.887 & 12,73 & 2.811 & 19,26 \\
\hline Acima de 51 anos & 87.215 & 2,86 & 634 & 4,34 \\
\hline Não informou & 23 & 0,00 & 0 & 0 \\
\hline \multicolumn{7}{l}{ Total } & $\mathbf{1 0 0}$ & $\mathbf{1 4 . 5 9 5}$ & $\mathbf{1 0 0}$ \\
\hline * Incluídas as pessoas com deficiência. \\
** Portador de Deficiência.
\end{tabular}

136 - Est. Aval. Educ., São Paulo, v. 21, n. 45, p. 127-144, jan./abr. 2010 
Há uma tendência dos candidatos com deficiência a procurarem concursos públicos com mais idade do que os demais. Com isso, levantam-se questóes que merecem melhor investigação, como por exemplo: problemas na trajetória escolar, ocorrência de formaçáo escolar tardia, egressos da EJA, desemprego em decorrência de preconceito no setor privado, etc.

\section{DESEMPENHO}

Para analisar como tem sido a "concorrência" no universo que compreende o desempenho aferido por avaliação escrita (objetiva e/ou discursiva), valendo-se de conteúdos escolares gerais e específicos de carreira, verificaremos a relação de aprovados para comparar os resultados e tentar responder à problematizaçáo deste trabalho, ou seja, se as pessoas com deficiência dependem exclusivamente de cotas e permanecem concorrendo entre si, nos concursos públicos.

O volume de dados detalhados por cargo é de tal monta que sorteamos três concursos para fazer a análise sobre os habilitados e não habilitados, cada qual em um dos anos considerados. Esses concursos foram: 2005 - Estado do Rio Grande do Norte, vários cargos, com exigências de Nível Médio (regular e técnico) e diversas áreas de formação em Nível Superior; 2006 - Estado do Amapá, com exigências de Nível Médio, qualquer formação em Nível Superior e formação em Direito; 2007 - Distrito Federal, com cargos que exigiam formaçáo em Nível Médio e Superior.

A tabela 2 mostra os cargos que receberam inscriçóes de candidatos com deficiência. Vale destacar que, neste concurso, também foram abertas inscriçôes para cadastro reserva para os cargos de nível superior em Engenharia, Medicina, Odontologia e uma vaga reservada aos portadores de deficiência para o cargo de Taquígrafo, porém nenhum deles recebeu inscrição de pessoas com deficiência. Para o nível médio, apesar de haver uma vaga reservada para portadores de deficiência nos cargos com exigência de formação técnica em Enfermagem, Higiene Dental, Operador de Computador e Programador e formação de cadastro reserva para o cargo de Técnico de Enfermagem, nenhum candidato portador de deficiência se inscreveu. 
Tabela 2 - Inscritos/Escolaridade/Área de Formação/2005 - Rio Grande do Norte

\begin{tabular}{|c|c|c|c|c|c|}
\hline Escolaridade & Área de Formação & $\begin{array}{c}\text { Total de } \\
\text { Inscritos* }\end{array}$ & $\begin{array}{l}\text { Inscritos } \\
\text { P.D. }\end{array}$ & $N^{\circ}$ de vagas & $\begin{array}{c}\text { No de vagas } \\
\text { reservadas a } \\
\text { P.D. }\end{array}$ \\
\hline \multirow{5}{*}{ Ensino Superior } & Direito & 2663 & 14 & Cadastro Reserva & - \\
\hline & $\begin{array}{l}\text { Qualquer Área de } \\
\text { Formação }\end{array}$ & 6414 & 84 & $\begin{array}{c}67+\text { Cadastro } \\
\text { Reserva }\end{array}$ & 4 \\
\hline & Contabilidade & 492 & 3 & Cadastro Reserva & - \\
\hline & Análise de Sistemas & 326 & 2 & $\begin{array}{c}1+\text { Cadastro } \\
\text { Reserva }\end{array}$ & - \\
\hline & Biblioteconomia & 95 & 1 & Cadastro Reserva & - \\
\hline Ensino Médio & $\begin{array}{l}\text { Ensino Médio } \\
\text { Completo }\end{array}$ & 14749 & 166 & $\begin{array}{c}77+\text { Cadastro } \\
\text { Reserva }\end{array}$ & 4 \\
\hline Total & & 28263 & 270 & & \\
\hline
\end{tabular}

Conforme citamos anteriormente, o Decreto Federal no 3.298/99 prevê que os candidatos inscritos como portadores de deficiência, quando aprovados, deveráo configurar em duas listas. A primeira contendo a classificação geral obtida no concurso, e a segunda contemplando sua classificação entre os portadores de deficiência.

A tabela 3 indica, entre os candidatos inscritos como portadores de deficiência, quantos foram aprovados e as respectivas classificaçóes (considerando a lista geral). Para saber a classificação correspondente da lista especial, basta considerar a sequência listada na tabela 3, partindo da primeira colocação.

Dentre os seis cargos em que pessoas com deficiência concorreram (Tabela 2), apenas em dois deles lograram aprovação: no cargo de nível superior (Qualquer Área de Formação), dos 84 candidatos inscritos, 15 foram aprovados, e no cargo de nível médio, dos 166 candidatos com deficiência inscritos, 41 foram aprovados (Tabela 3).

A tabela 3 apresenta a classificação desses candidatos e verificamos que o primeiro candidato aprovado, dentre os portadores de deficiência, no cargo de nível superior, considerando-se sua classificação geral, ocupou a $70^{a}$ posiçáa, o segundo a $370^{a}$ colocaçáa, e assim sucessivamente, o que nos leva a crer que sem a reserva de vagas a possibilidade de um desses candidatos ser convocado para tomar posse seria remota. O mesmo se verifica em relaçáo aos candidatos aprovados para o cargo cuja exigência era o ensino médio completo. $\mathrm{O}$ primeiro colocado da lista especial, teve sua classificação geral na $130^{a}$ posição, o que tornaria a possibilidade de nomeação ainda mais remota, sem a reserva de vagas. 
Tabela 3 - Aprovados/Classificação/2005 - Rio Grande do Norte

\begin{tabular}{|c|c|c|c|c|c|}
\hline \multirow{2}{*}{ Escolaridade } & \multicolumn{3}{|c|}{ Pessoas com Deficiência } & \multicolumn{2}{|c|}{ Total } \\
\hline & Inscritos & Aprovados & Classificação Geral & Inscritos & Aprovados \\
\hline $\begin{array}{l}\text { Ensino Superior } \\
\text { Qualquer área de } \\
\text { formação }\end{array}$ & 84 & 15 & $\begin{array}{c}\text { 70/370/500/631/807/821/ } \\
854 / 1066 / 1123 / 1181 / 1306 / \\
1345 / 1392 / 1437 / 1443\end{array}$ & 6414 & 1492 \\
\hline Ensino Médio & 166 & 41 & $\begin{array}{c}130 / 159 / 224 / 243 / 251 / 309 / \\
452 / 661 / 688 / 689 / 695 / 738 / \\
760 / 869 / 1128 / 1300 / 1384 / \\
1424 / 1687 / 1713 / 2003 / 2014 / \\
2020 / 2050 / 2174 / 2274 / 2381 / \\
2422 / 2466 / 2517 / 2634 / 2698 / \\
2703 / 2706 / 2771 / 2776 / 2828 / \\
2862 / 2904 / 3047 / 3326\end{array}$ & 14749 & 3415 \\
\hline
\end{tabular}

No concurso de 2006, com número reduzido de pessoas com deficiência inscritas nos cargos de nível superior (Tabela 4), não houve aprovação de nenhum desses candidatos. Dentre os 33 inscritos ao cargo de nível médio, 4 deles foram aprovados. Entretanto, observamos a mesma situação exposta anteriormente: o primeiro portador de deficiência aprovado, na classificação geral, ocupa a $134^{\text {a }}$ colocação (Tabela 5), o que significa que sem a reserva de vagas a possibilidade de nomeaçáo seria pouco provável.

Tabela 4 - Inscritos/Escolaridade/Área de Formação/2006 - Amapá

\begin{tabular}{l|l|c|c|c|c}
\hline \multirow{2}{*}{ Escolaridade } & \multicolumn{1}{|c|}{ Área de Formação } & $\begin{array}{c}\text { Total de } \\
\text { Inscritos* }\end{array}$ & $\begin{array}{c}\text { Inscritos } \\
\text { P. D. }\end{array}$ & $\begin{array}{c}\mathbf{N}^{\circ} \text { de } \\
\text { vagas }\end{array}$ & $\begin{array}{c}\mathbf{N}^{\circ} \text { de vagas } \\
\text { reservadas a } \\
\text { P. D. }\end{array}$ \\
\hline \multirow{2}{*}{ Ensino Superior } & Qualquer área de formação & 953 & 3 & 4 & 1 \\
\cline { 2 - 6 } & Direito & 433 & 1 & 11 & 1 \\
\hline Ensino Médio & Ensino Médio & 8834 & 33 & 22 & 2 \\
\hline Total & $\mathbf{1 0 2 2 0}$ & $\mathbf{3 7}$ & & \\
\hline
\end{tabular}

* Incluídas as pessoas com deficiência. 
Tabela 5 - Aprovados/Classificação/2006 - Amapá

\begin{tabular}{c|c|c|c|c|c}
\hline \multirow{2}{*}{ Escolaridade } & \multicolumn{3}{|c|}{ Pessoas com Deficiência } & \multicolumn{2}{c}{ Total } \\
\cline { 2 - 6 } & Inscritos & Aprovados & Classificação Geral & Inscritos & Aprovados \\
\hline Ensino Médio & 33 & 4 & $134 / 360 / 672 / 729$ & 5188 & 869 \\
\hline
\end{tabular}

Fonte: Diário Oficial da União - Seção 3, de 03/04/2006.

No concurso analisado de 2007, a tabela 6 mostra que em todos os cargos oferecidos havia candidatos com deficiência concorrendo às vagas, e o número pode ser considerado expressivo, pois a quantidade de inscritos com deficiência ultrapassa a marca de $1 \%$. Com exceção dos cargos que exigiam formação em Arquivologia e Nutrição, em todos os outros tivemos candidatos com deficiência aprovados.

Tabela 6 - Inscritos/ Escolaridade/Área de Formação/2007 - Distrito Federal

\begin{tabular}{l|l|r|r|r|c}
\hline \multirow{2}{*}{ Escolaridade } & \multicolumn{1}{|c|}{ Área de Formação } & $\begin{array}{c}\text { Total de } \\
\text { Inscritos* }\end{array}$ & $\begin{array}{c}\text { Inscritos } \\
\text { P. D. }\end{array}$ & $\begin{array}{c}\text { No de } \\
\text { vagas }\end{array}$ & $\begin{array}{c}\text { No de vagas } \\
\text { reservadas a } \\
\text { P. D. }\end{array}$ \\
\hline \multirow{2}{*}{ Ensino Superior } & Qualquer Área de Formação & 7411 & 128 & 12 & 1 \\
\cline { 2 - 6 } & $\begin{array}{l}\text { Qualquer Área de Formação (função } \\
\text { ligada à Informática) }\end{array}$ & 8670 & 92 & 20 & 1 \\
\cline { 2 - 6 } & Bibliotecário & 1312 & 18 & 14 & 1 \\
\cline { 2 - 6 } & Arquivologista & 609 & 6 & 6 & 1 \\
\cline { 2 - 6 } & Nutricionista & 1407 & 24 & 2 & 1 \\
\hline Ensino Médio & Ensino Médio & 54321 & 599 & 90 & 5 \\
\hline Total & $\mathbf{7 3 7 3 0}$ & $\mathbf{8 6 7}$ & & \\
\hline * Incluídas as pessoas com deficiência. & & & &
\end{tabular}

Neste concurso, observamos situação comum às análises anteriores: os primeiros candidatos com deficiência aprovados em cada cargo tiveram, respectivamente, sua classificação geral nas seguintes posiçóes: 46, 94 e 138 (Tabela 7).

Entretanto, temos duas exceçôes: para o cargo de Bibliotecário e Nutricionista, os primeiros candidatos com deficiência aprovados, aparecem em segundo lugar na classificação geral. De todos os cargos analisados neste trabalho, seriam as únicas situaçóes em que a cota não seria fator determinante para garantir o ingresso da pessoa com deficiência no mercado de trabalho, no caso, no serviço público.

140 • Est. Aval. Educ., São Paulo, v. 21, n. 45, p. 127-144, jan./abr. 2010 
Tabela 7 - Aprovados/Classificação/2007 - Distrito Federal

\begin{tabular}{|c|c|c|c|c|c|}
\hline \multirow{2}{*}{ Escolaridade } & \multicolumn{3}{|c|}{ Pessoas com Deficiência } & \multicolumn{2}{|c|}{ Total } \\
\hline & Inscritos & Aprovados & Classificação Geral & Inscritos & Aprovados \\
\hline \multirow{4}{*}{ Ensino Superior } & $128^{(1)}$ & 5 & $46 / 90 / 127 / 244 / 266$ & 7411 & 285 \\
\hline & $92^{(2)}$ & 4 & $94 / 255 / 325 / 425$ & 8770 & 479 \\
\hline & $18^{(3)}$ & 3 & $2 / 32 / 48$ & 1312 & 77 \\
\hline & $24^{(4)}$ & 2 & $2 / 93$ & 1404 & 107 \\
\hline Ensino Médio & 599 & 66 & \begin{tabular}{|c|}
$138 / 270 / 367 / 586 / 730 / 916 /$ \\
$1368 / 1368 / 1368 / 1629 / 1893 / 189$ \\
$3 / 2209 / 2209 / 2209 / 2209 / 2562 / 25$ \\
$62 / 2562 / 2562 / 2562 / 2932 / 2932 / 2$ \\
$932 / 3372 / 3372 / 3372 / 3852 / 3852 /$ \\
$3852 / 3852 / 4335 / 4335 / 4335 / 487$ \\
$5 / 4875 / 5478 / 5478 / 5478 / 5478 / 54$ \\
$78 / 6134 / 6134 / 6134 / 6134 / 6134 / 6$ \\
$134 / 6134 / 6826 / 6826 / 6826 / 6826 /$ \\
$6826 / 6826 / 6826 / 6826 / 6826 / 682$ \\
$6 / 6826 / 6826 / 7539 / 7539 / 7539 / 75$ \\
$39 / 7539 / 7539$
\end{tabular} & 54320 & 8327 \\
\hline \multicolumn{6}{|c|}{$\begin{array}{l}\text { (1) Cargo que exigia qualquer área de formação. } \\
\text { (2) Qualquer área de formação - Função ligada à Informática. } \\
\text { (3) Formação em Biblioteconomia. } \\
\text { (4) Formação em Nutrição. } \\
\text { Fonte: Diário Oficial da União - Seção 3, de 03/10/2007. }\end{array}$} \\
\hline
\end{tabular}

No geral, em relação à classificação, os dados coletados e analisados nos sugerem que entre as pessoas com deficiência que concorreram aos cargos de nível superior, o índice de aprovaçấo é significativamente inferior aos aprovados nos cargos de nível médio. Nos concursos analisados, nos cargos de nível superior temos: $17 \%$ dos inscritos com deficiência aprovados no Rio Grande do Norte, 0\% no Amapá e 5\% no Distrito Federal. Nos cargos de nível médio comparando o total de portadores de deficiência inscritos ao total de aprovados temos: $25 \%$ de pessoas com deficiência aprovadas no Rio Grande do Norte, $12 \%$ no Amapá e 11\% no Distrito Federal. Porém, se considerada sua classificação no quadro geral de aprovados, sem a reserva de cotas, suas chances de serem chamados para tomar posse seriam remotas.

\section{CONSIDERAÇÕES FINAIS}

Nos concursos estudados, a relaçáo do primeiro colocado na lista especial (somente dos candidatos com deficiência) com a lista geral (classificação de todos os 
inscritos) mostra que sem as cotas, a possibilidade desses candidatos serem nomeados seria pouco provável. Dos dados apresentados, duas exceções: os primeiros, dentre os classificados com deficiência, ocupam o segundo lugar na lista geral (concurso de 2007), o que lhes garantiria ingresso na respectiva carreira.

A lei de cotas promulgada em 1999 reserva, no mínimo, 5\% das vagas públicas às pessoas com deficiência, contudo, passados 8 anos, mesmo com o referido amparo legal, essa população ainda não atingiu $1 \%$ do número total de pessoas inscritas nos concursos. Podemos considerar, porém não afirmar, que a lei de cotas, no serviço público, tem garantido o ingresso das pessoas com deficiência no mercado trabalho, embora os 5\% de vagas não sejam atingidos, por falta de inscritos e/ou de aprovados; entretanto abre-se aqui questionamento acerca da existência do amparo legal e das condiçóes oferecidas previamente, no caso, educacionais/escolares, para que o cidadão realmente se beneficie de tal ação afirmativa.

Considerando a aplicabilidade do decreto, a constatação da ínfima participaçáo nos concursos e, principalmente, as classificaçóes obtidas pelos candidatos com deficiência, no que toca à importância deste estudo, do real compromisso e anseio pela educação inclusiva e de uma sociedade inclusiva, esta pesquisa assinala para a relevância de futuras investigaçóes que possam aprofundar o estudo, contribuindo para que as populaçóes, tidas como minorias, possam usufruir dos direitos que lhes são assegurados.

\section{REFERÊNCIAS BIBLIOGRÁFICAS}

AZEVEDO, J. Entre a escola e o mercado de trabalho: um olhar crítico sobre as transições. In: GIL, Hernandes Carlos; MARCHESI, Álvaro. (Org.). Fracasso escolar uma perspectiva multicultural. Porto Alegre: Artmed, 2004. p. 161-176.

BATISTA, A. A. O Trabalho e a educação da pessoa cega ou com visão reduzida na sociedade capitalista contemporânea. In: SEMINARIO DE CEGOS, 7., 2007, Cascavel. Anais... Cascavel: ACADEVI, 2007.

BRASIL. Presidência da República. Constituição da República Federativa: 1988. Disponível em: <http://www.mj.gov.br/sedh/ct/corde/dpdh/ legis1/legislacao4.asp\#conteudo>. Acesso em: 08 mar. 2008.
BRASIL. Decreto n.o 914. Institui a política nacional para a integração da pessoa portadora de deficiência, e dá outras providências. Brasília, 1993. Disponível em: <http://www.mj.gov.br/sedh/ct/corde/dpdh/ legis1/legislacao4.asp\#conteudo>. Acesso em: 08 mar. 2008.

. Decreto n. 3.298. Regulamenta a Lei n. ${ }^{\circ} 7.853$, Dispõe sobre a política nacional para a integração da pessoa portadora de deficiência, consolida as normas de proteção, e dá outras providências. Disponível em <http://www.mj.gov.br/sedh/ct/corde/dpdh/ legis1/legislacao4.asp\#conteudo>. Acesso em: 08 mar. 2008.

BRASIL. Lei n. ${ }^{0}$ 9.394. Lei de Diretrizes e 
Bases da Educação Nacional. DOU, 20 dez. 1996. Disponível em: <http://www.mj.gov. br/sedh/ct/corde/dpdh/legis1/legislacao4. asp\#conteudo>. Acesso em: 08 mar. 2008.

BRASÍLIA. Coordenadoria Nacional para Integração da Pessoa Portadora de Deficiência (Corde). Declaração de Salamanca e linhas de ação sobre necessidades educativas especiais. 1994. Disponível em: <http://www.mj.gov.br/ sedh/ct/corde/dpdh/sicorde/document_int. asp\#conteudo>. Acesso em: 08 mar. 2008.

BUENO, J. G. S. As Políticas de inclusão escolar: uma prerrogativa da educação especial? In: BUENO, J. G. S.; LUNARDI, M.; SANTOS, A. R. (Org.). Deficiência $e$ escolarização: novas perspectivas de análise. Araraquara, SP: Junqueira \& Marin; Brasília, DF: Capes, 2008.

FERRETTI, C. J. Considerações sobre a apropriação das noções de qualificação profissional pelos estudos a respeito das relações entre trabalho e educação. Educação \& Sociedade, v. 25, n. 87, p.401-422, 2004.

GUGEL, M. A. Pessoas com deficiência e o direito ao concurso público: reserva de cargos e empregos públicos, administração pública direta e indireta. Goiânia: UCG, 2006.

PATTO, M. H. S. Políticas atuais de inclusão escolar: reflexão a partir de um recorte conceitual. In: BUENO, J. G. S.; LUNARDI, M.; SANTOS, A.R. (Org.). Deficiência e escolarização: novas perspectivas de análise. Araraquara, SP: Junqueira \& Marin; Brasília, DF: Capes, 2008.

TARTUCE, G. L. B. P. Tensões e intenções na transição escola-trabalho: um estudo das vivências e percepções de jovens sobre os processos de qualificação profissional e (re) inserção no mercado de trabalho na cidade de São Paulo. São Paulo, 2007. Tese (Doutorado em Sociologia) - Universidade de São Paulo.

Recebido em: outubro 2009

Aprovado para publicação em: fevereiro 2010 